\title{
Compressibility and thermal expansion of cubic silicon nitride
}

Jiang, Jianzhong; Lindelov, H.; Gerward, Leif; Ståhl, Kenny; Recio, R.M.; Mori-Sanchez, P.; Carlson, S.; Mezouar, M.; Dooryhee, E.; Fitch, A.

Total number of authors:

11

Published in:

Physical Review B Condensed Matter

Link to article, DOI:

10.1103/PhysRevB.65.161202

Publication date:

2002

Document Version

Publisher's PDF, also known as Version of record

Link back to DTU Orbit

Citation (APA):

Jiang, J., Lindelov, H., Gerward, L., Ståhl, K., Recio, R. M., Mori-Sanchez, P., Carlson, S., Mezouar, M., Dooryhee, E., Fitch, A., \& Frost, D. J. (2002). Compressibility and thermal expansion of cubic silicon nitride. Physical Review B Condensed Matter, 65(16), 161202. https://doi.org/10.1103/PhysRevB.65.161202

\section{General rights}

Copyright and moral rights for the publications made accessible in the public portal are retained by the authors and/or other copyright owners and it is a condition of accessing publications that users recognise and abide by the legal requirements associated with these rights.

- Users may download and print one copy of any publication from the public portal for the purpose of private study or research.

- You may not further distribute the material or use it for any profit-making activity or commercial gain

- You may freely distribute the URL identifying the publication in the public portal 


\title{
Compressibility and thermal expansion of cubic silicon nitride
}

\author{
J. Z. Jiang,* H. Lindelov, and L. Gerward \\ Department of Physics, Building 307, Technical University of Denmark, DK-2800 Lyngby, Denmark \\ K. Ståhl \\ Department of Chemistry, Building 207, Technical University of Denmark, DK-2800 Lyngby, Denmark
}

J. M. Recio* and P. Mori-Sanchez
Departamento de Quimica Fisica y Analitica, Facultad de Quimica, Universidad de Oviedo, E-33006 Oviedo, Spain

S. Carlson, M. Mezouar, E. Dooryhee, and A. Fitch

European Synchrotron Radiation Facility (ESRF), Boite Postal 220, 38000 Grenoble, France

D. J. Frost

Bayerisches Geoinstitut, Universität Bayreuth, D-95440 Bayreuth, Germany

(Received 27 August 2001; revised manuscript received 11 February 2002; published 8 April 2002)

\begin{abstract}
The compressibility and thermal expansion of the cubic silicon nitride $\left(c-\mathrm{Si}_{3} \mathrm{~N}_{4}\right)$ phase have been investigated by performing in situ x-ray powder-diffraction measurements using synchrotron radiation, complemented with computer simulations by means of first-principles calculations. The bulk compressibility of the $c-\mathrm{Si}_{3} \mathrm{~N}_{4}$ phase originates from the average of both $\mathrm{Si}-\mathrm{N}$ tetrahedral and octahedral compressibilities where the octahedral polyhedra are less compressible than the tetrahedral ones. The origin of the unit cell expansion is revealed to be due to the increase of the octahedral $\mathrm{Si}-\mathrm{N}$ and $\mathrm{N}-\mathrm{N}$ bond lengths with temperature, while the lengths for the tetrahedral Si-N and N-N bonds remain almost unchanged in the temperature range 295-1075 K.
\end{abstract}

DOI: 10.1103/PhysRevB.65.161202

PACS number(s): 65.40.De, 61.10.Eq, 62.20.Fe, 62.50.+p

Recently, after the discovery of a third polymorph of silicon nitride $\left(c-\mathrm{Si}_{3} \mathrm{~N}_{4}\right)$ synthesized under high-pressure and high-temperature conditions, ${ }^{1}$ there has been considerable interest in this field. ${ }^{2-11}$ The structure of the material has been determined as a cubic spinel structure at ambient temperature. ${ }^{1,3-5}$ It possesses a hardness of about $35.3 \mathrm{GPa},{ }^{9}$ significantly greater than the hardness of the two longestablished hexagonal polymorphs: $\alpha$ - and $\beta-\mathrm{Si}_{3} \mathrm{~N}_{4}$ and slightly harder than that of the stishovite, a high-pressure phase of $\mathrm{SiO}_{2}$ and hardness of $33 \mathrm{GPa} .{ }^{12}$ Besides, the material is stable against oxidation in air up to a temperature of $1673 \mathrm{~K} .{ }^{9}$ These excellent properties make the $c-\mathrm{Si}_{3} \mathrm{~N}_{4}$ polymorph a promising candidate as an advanced superhard material. The precise knowledge of the compressibility and thermal expansion of the material is of great interest for several practical reasons. Hence, the zero pressure bulk modulus of $c-\mathrm{Si}_{3} \mathrm{~N}_{4}$ has been intensively investigated. However, there is a large scatter of the values reported, $300,{ }^{1} 280,{ }^{2} 411.9,{ }^{6}$ $308,{ }^{8} 284,{ }^{8}$ and $407 \mathrm{GPa}$ (Ref. 10) obtained from theoretical calculations, 300(10) GPa from Hugoniot data ${ }^{7}$ and 308(5) GPa from energy-dispersive x-ray powder-diffraction (XRD) measurements. ${ }^{8}$ No study of the thermal-expansion behavior of the material has been reported in spite of its relevance in the practical applications of this superhard material. For example, the differences in thermal-expansion coefficients between the substrate and $c-\mathrm{Si}_{3} \mathrm{~N}_{4}$ determine the thermal stress component. In this work, we report the compressibility and thermal-expansion behavior of the $c-\mathrm{Si}_{3} \mathrm{~N}_{4}$ phase by in situ $\mathrm{x}$-ray powder-diffraction measurements using synchrotron radiation, complemented with computer simulations by means of first-principles calculations.
A multianvil octahedra pressure assembly was employed in the synthesis of the cubic spinel $\mathrm{Si}_{3} \mathrm{~N}_{4}$ phase. A mixture of $\alpha$ - and $\beta-\mathrm{Si}_{3} \mathrm{~N}_{4}$ powders was compressed at $17 \pm 0.5 \mathrm{GPa}$ and $2100 \mathrm{~K}$ for $1 \mathrm{~h}$. The temperature of the experiment was monitored using a W-3\% Re-W-25\% Re thermocouple. Further detail for sample preparation is given in Ref. 5. The recovered sample (about $10 \mathrm{mg}$ in weight) was composed of light-yellow transparent sintered crystals with an average grain size of approximately $140 \mathrm{~nm}$ determined by optical and scanning electron microscopy and x-ray powder diffraction. Secondary-ion mass spectroscopy measurements on the recovered sample revealed an oxygen impurity less than 1 at. $\%$.

In situ high-temperature (295-1075 $\mathrm{K}$ in vacuum) and high-pressure (up to $42 \mathrm{GPa}$ at ambient temperature) x-ray powder-diffraction measurements were performed using synchrotron radiation at beamlines BM16 and ID30, respectively, at ESRF in Grenoble, France. The powder sample, ground from the recovered sample, was placed in an amorphous quartz capillary, pumped down to $10^{-5}$ mbar and then sealed, and rotated during data collections with a multichannel detector $\left(0.003^{\circ}\right.$ accuracy) and a wavelength of 0.71031 $\AA$. A hot air gun was used for high-temperature measurements. The temperature at sample was calibrated using the known temperature dependence of lattice parameter for pure silicon powder in place of the sample position. ${ }^{13}$ A diamondanvil cell with solid Ar as pressure transmitting medium was used for room-temperature compression XRD measurements up to $42 \mathrm{GPa}$ with an image plate mounted on a Fastscan-II detector and a wavelength of $0.3738 \AA$. The actual pressure was calculated from the wavelength shift of the ruby line 


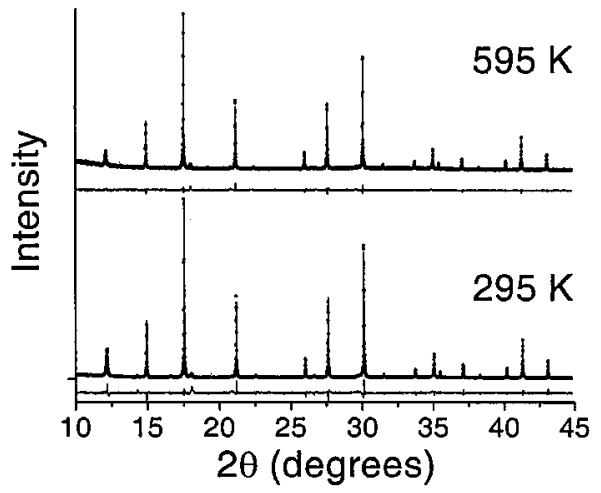

(a)

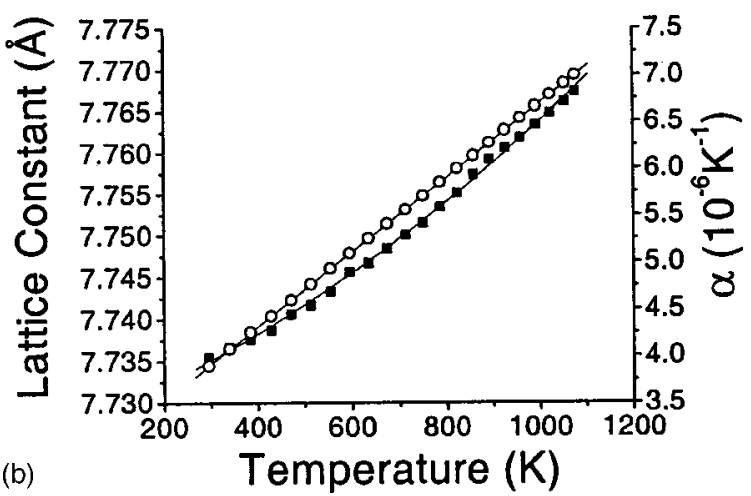

FIG. 1. (a) Rietveld structural refinement profiles of two x-ray powder-diffraction data recorded at 295 and $595 \mathrm{~K}$ for the cubic spinel $\mathrm{Si}_{3} \mathrm{~N}_{4}$ phase. (b) The lattice parameter (solid squares) and the linear thermal expansion coefficient (open circles) of the $c-\mathrm{Si}_{3} \mathrm{~N}_{4}$ phase together with fitted curves.

using the nonlinear pressure scale of Mao et al. ${ }^{14}$ The Rietveld refinement program is a local variation of the LHMP1 program, ${ }^{17}$ using the Voigt profile function and Chebyshev polynomial background fitting.

First-principles CRYSTAL calculations ${ }^{15,16}$ were performed under the density-functional approximation using the Becke and Perdew-Wang nonlocal exchange and correlation functionals ${ }^{17}$ respectively. Si and N standard Gaussian-type basis sets of triple- $\zeta$ quality were adapted to this crystalline structure. The lattice parameter $a$ and the nitrogen internal position $(u, u, u)$ were accurately determined by requiring the total energy of the crystal to be minimum in a set of volume points below and above the experimental equilibrium geometry. Thermal effects on the crystal energy were evaluated through a quasiharmonic nonempirical Debye model that only needs the computed static bulk modulus value as input (details are given in Ref. 18).

High-temperature XRD patterns, recorded in steps of 40 $\mathrm{K}$ from 295 to $1075 \mathrm{~K}$ for the $c-\mathrm{Si}_{3} \mathrm{~N}_{4}$ phase, are identical except for the thermal expansion. Figure 1(a) exemplifies two Rietveld structure refined XRD patterns recorded at 295 and $595 \mathrm{~K}$. All refinements converged to small residual values. No phase transformation was detected in the temperature range $295-1075 \mathrm{~K}$ in vacuum, in agreement with previous data reported for the $c-\mathrm{Si}_{3} \mathrm{~N}_{4}$ sample annealed in air in a temperature range from 295 to $1673 \mathrm{~K} .^{9}$ The lattice parameter $a$ and the linear thermal-expansion coefficient $\alpha$ of the
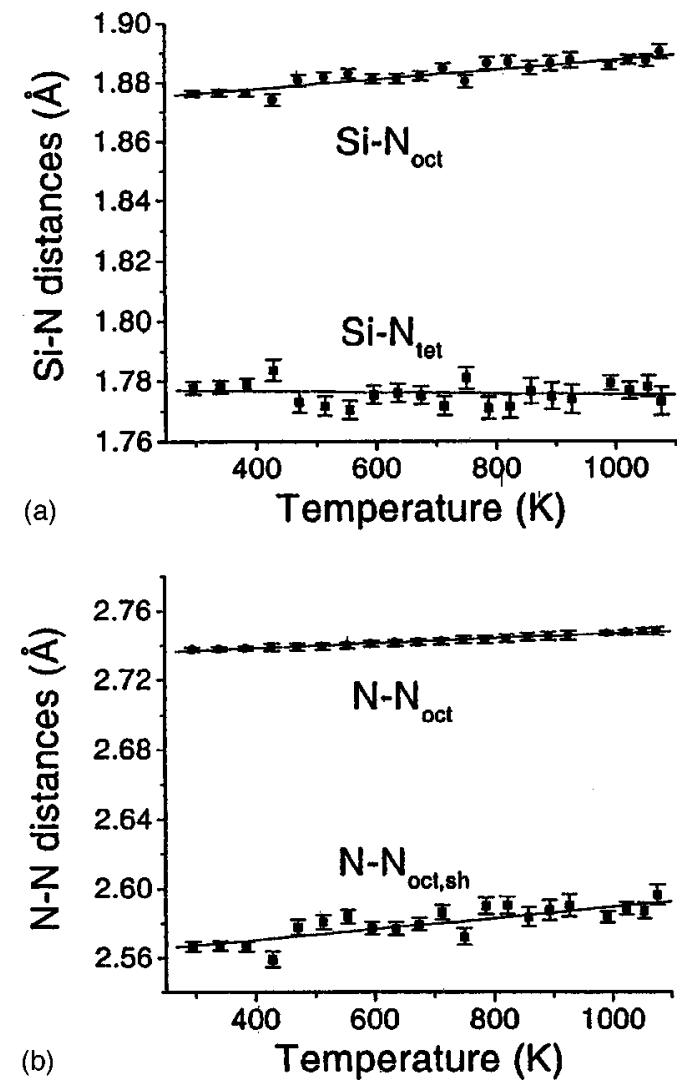

FIG. 2. Temperature dependences of bond lengths for the tetrahedral and octahedral Si-N pairs (a) and N-N pairs (b) obtained from the Rietveld structural refinements for the $c-\mathrm{Si}_{3} \mathrm{~N}_{4}$ phase.

$c-\mathrm{Si}_{3} \mathrm{~N}_{4}$ phase are shown in Fig. 1(b). The data are fitted with a polynomial function (solid line), $a=7.7274+2.0893$ $\times 10^{-5} T+1.5537 \times 10^{-8} T^{2}$. Here $\alpha$ is defined as $\alpha$ $=(d a / d T) / a$. It is clear that $\alpha$ increases linearly with temperature and can be described with $\alpha=2.716 \times 10^{-6} \mathrm{~K}^{-1}$ $+0.004 \times 10^{-6} T$. The linear thermal-expansion coefficient at $295 \mathrm{~K}$ for the $c-\mathrm{Si}_{3} \mathrm{~N}_{4}$ phase is $\alpha=3.89 \times 10^{-6} \mathrm{~K}^{-1}$, which is about three times larger than $1.19 \times 10^{-6} \mathrm{~K}^{-1}$ at $300 \mathrm{~K}$ for $\beta$ - $\mathrm{Si}_{3} \mathrm{~N}_{4}$ (Refs. 19 and 20) and about four times larger than $1.05 \times 10^{-6} \mathrm{~K}^{-1}$ at $300 \mathrm{~K}$ for diamond. ${ }^{21}$ Our theoretical result $\alpha=3.16 \times 10^{-6} \mathrm{~K}^{-1}$ at $300 \mathrm{~K}$ supports the experimental data. The calculated lattice parameter and $\mathrm{N}$ position at $300 \mathrm{~K}$ are, respectively, 7.860 (only 1\% larger than the experimental value) and $0.2576 \AA$ (close to 0.2583 from the experiments of Ref. 5). The specific heat capacity at constant volume, $C_{v}=0.66 \mathrm{~J} \mathrm{~g}^{-1} \mathrm{~K}^{-1}$, Gruneisen parameter $\gamma$ $=1.23$, and Debye temperature $\theta_{D}=1150 \mathrm{~K}$, obtained from the simulations at $300 \mathrm{~K}$ show also a good agreement with available empirical estimations for this $c-\mathrm{Si}_{3} \mathrm{~N}_{4}$ phase, collected in Ref. 7. Figure 2 depicts the temperature dependences of the bond lengths for the tetrahedral and octahedral sites, obtained from the Rietveld structural refinements. It is clear that the octahedral $\mathrm{Si}-\mathrm{N}$ bond length increases with temperature, $d=1.871 \AA+1.610 \times 10^{-5} T$, while the length for the tetrahedral $\mathrm{Si}-\mathrm{N}$ bond remains almost unchanged within the experimental uncertainty. Both octahedral N-N bond lengths, shared $\mathrm{N}-\mathrm{N}_{\text {oct, th }} d=2.558 \AA+3.197 \times 10^{-5} T$, 

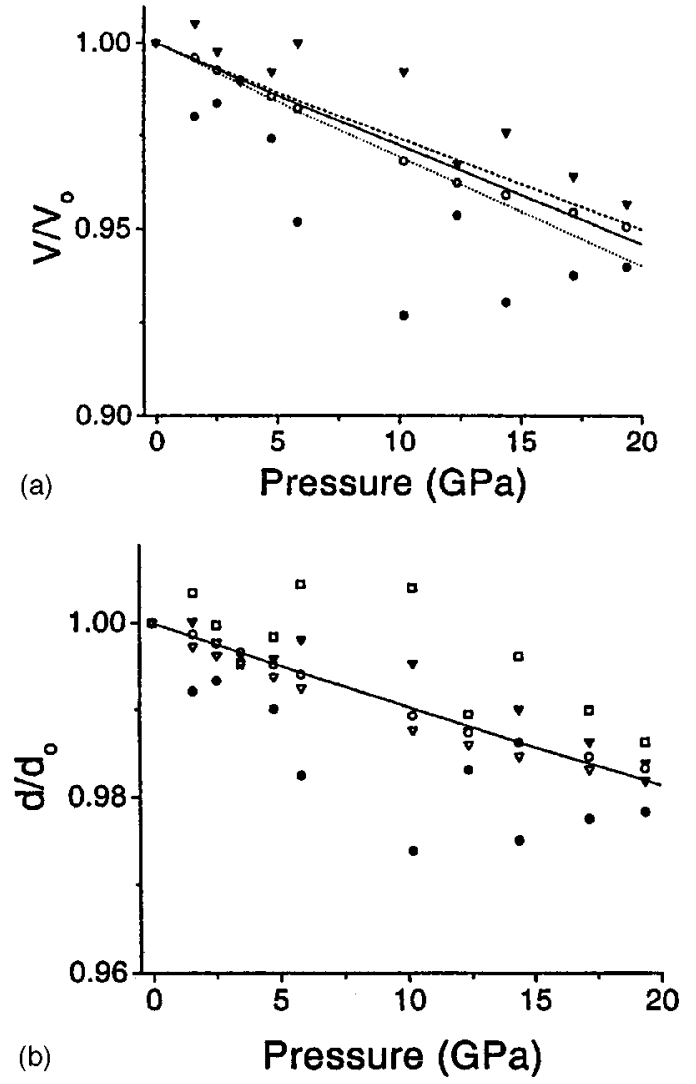

FIG. 3. (a) The reduced unit-cell volume data (open circles), octahedral Si-N polyhedra (solid triangles), and tetrahedral Si-N polyhedra (solid circles), as a function of pressure during compression for the $c-\mathrm{Si}_{3} \mathrm{~N}_{4}$ phase, together with the theoretical results for the reduced unit-cell volume (solid line), for octahedral Si-N polyhedra (dashed line) and for tetrahedral Si-N polyhedra (dotted line). (b) The reduced lattice constant (open circles), octahedral Si-N (solid triangles) and tetrahedral Si-N (solid circles), and both octahedral shared $\mathrm{N}-\mathrm{N}_{\text {oct,sh }}$ (open squares) and unshared $\mathrm{N}-\mathrm{N}_{\text {oct }}$ (open triangles) bond lengths as a function of pressure during compression for the $c-\mathrm{Si}_{3} \mathrm{~N}_{4}$ phase, together with the solid line for the reduced lattice constant obtained from the theoretical calculations.

and unshared $\mathrm{N}-\mathrm{N}_{\text {oct }}, d=2.733 \AA+1.404 \times 10^{-5} \mathrm{~T}$, edges of the Si-N octahedral, increase with temperature while the length for the tetrahedral N-N bond $\left[d_{\mathrm{N}-\mathrm{N}_{\mathrm{tet}}} d_{\mathrm{Si}-\mathrm{N}_{\mathrm{tet}}}=1.633\right.$, not shown in Fig. 2(b)] remains almost unchanged. The octahedral Si-N bond angle varies randomly around $86.35^{\circ}$ $\pm 0.06^{\circ}$ in the whole temperature range while the tetrahedral $\mathrm{Si}-\mathrm{N}$ bond angle is constant of 109.47 due to the symmetry. The strong temperature dependence of the octahedral Si-N and N-N bonds causes a large linear thermal-expansion coefficient at $295 \mathrm{~K}$ for the $c-\mathrm{Si}_{3} \mathrm{~N}_{4}$ phase as compared to $\beta$ - $\mathrm{Si}_{3} \mathrm{~N}_{4}$ because in $\beta-\mathrm{Si}_{3} \mathrm{~N}_{4}$ only tetrahedral bonds exist. This picture is consistent with the results observed in Ref. 19 , i.e., the thermal expansion for tetrahedral bonds is smaller than that for octahedral bonds.

A large number of XRD patterns were recorded at pressures ranging from 0 to approximately $42 \mathrm{GPa}$ at ambient temperature. Up to a pressure of $42 \mathrm{GPa}$, no phase transformation was observed. At pressures above $20 \mathrm{GPa}$, Bragg peaks become broadened and strain deduced from Rietveld
TABLE I. Collected values of the bulk modulus at zero pressure, $B_{0}$, and the first pressure derivative, $B_{0}^{\prime}$, for the $c-\mathrm{Si}_{3} \mathrm{~N}_{4}$ phase. The lower part of the table contains the results obtained in this work.

\begin{tabular}{|c|c|c|}
\hline$B_{0}(\mathrm{GPa})$ & $B_{0}^{\prime}$ & Comments \\
\hline 300 & & Theoretical (Ref. 1) \\
\hline 280 & 3.48 & Theoretical (Ref. 2) \\
\hline 411.9 & & Theoretical (Ref. 6) \\
\hline 308 & 3.9 & Theoretical (Ref. 8) \\
\hline 284 & 3.9 & Theoretical (Ref. 8) \\
\hline 305 & & Theoretical (Ref. 8) \\
\hline 407 & 3.33 & Theoretical (Ref. 10) \\
\hline $300 \pm 10$ & $3.0 \pm 0.1$ & Experimental (Ref. 7) \\
\hline $308 \pm 5$ & $4.0 \pm 0.2$ & Experimental (Ref. 8) \\
\hline 328 & 2.8 & Theoretical (bulk) \\
\hline 361 & 2.9 & Theoretical (Si-N octahedra) \\
\hline 298 & 2.6 & Theoretical (Si-N tetrahedra) \\
\hline $309 \pm 3$ & 4.0 fixed & Experimental \\
\hline $317 \pm 11$ & $2.3 \pm 2.1$ & Experimental \\
\hline
\end{tabular}

structural refinements starts to increase with pressure. The results infer that a transition from a hydrostatic state below $20 \mathrm{GPa}$ into a nonhydrostatic one above $20 \mathrm{GPa}$ occurs for the sample in the diamond-anvil cell. Hence, pressurevolume data below $20 \mathrm{GPa}$ will be further used to explore the compression behavior of the $c-\mathrm{Si}_{3} \mathrm{~N}_{4}$ phase. Figure 3 shows the reduced unit-cell volume data, octahedral $\mathrm{Si}-\mathrm{N}$ polyhedra, $V_{\text {oct }}=128 V\left(u-\frac{3}{8}\right)^{2} u / 3$, and tetrahedral Si-N polyhedra, $V_{\text {tet }}=64 V(u-1 / 8)^{3} / 3$ [Fig. 3(a)], where $V$ is the unit-cell volume. Also shown are the reduced lattice constant, octahedral and tetrahedral Si-N bond lengths, and both octahedral shared $\mathrm{N}-\mathrm{N}_{\text {oct } / \mathrm{sh}}$ and unshared $\mathrm{N}-\mathrm{N}_{\text {oct }}$ bond lengths as a function of pressure during compression [Fig. $3(\mathrm{~b})$ ]. The octahedral $\mathrm{Si}-\mathrm{N}$ bond angle varies randomly around $86.58^{\circ} \pm 0.15^{\circ}$ in the whole pressure range while the tetrahedral Si-N bond angle is constant of 109.47 due to the symmetry. The bulk modulus at zero pressure, $B_{0}$, and the first pressure derivative, $B_{0}^{\prime}$, for the $c-\mathrm{Si}_{3} \mathrm{~N}_{4}$ phase at ambient temperature are found to be $317 \pm 11 \mathrm{GPa}$ and $2.3 \pm 2.1$ or $309 \pm 3 \mathrm{GPa}$ and 4.0 (constrained), respectively, using the Birch equation of state. ${ }^{22}$ These and other data are listed in Table I. The experimental values of $B_{0}$ and $B_{0}^{\prime}$, obtained here are in good agreement with data reported in Refs. 1, 2, 7, 8 . We found that the $\mathrm{Si}-\mathrm{N}$ octahedral polyhedra are slightly less compressible than the Si-N tetrahedral ones, although there is some scatter in the experimental data due to a large uncertainty of the parameter $u$ estimated from the Rietveld structural refinements. The bulk modulus of the $c-\mathrm{Si}_{3} \mathrm{~N}_{4}$ phase can be estimated as the average of both tetrahedral and octahedral moduli, which are controlled by the $\mathrm{Si}-\mathrm{N}$ pair, as illustrated by the linear curve in Fig. 3(b). The computed pressure diagrams for reduced volumes [Fig. 3(a)] and bond lengths [Fig. 3(b)] are consistent with the experimental points. Besides, the theoretical results predict the same compressibility sequence obtained in the XRD measurements for polyhedra and distances. In Table I, we include computed 
polyhedral and bulk equation of state parameters at $300 \mathrm{~K}$. Our calculations yield $B_{0}$ for the bulk only slightly overestimated with respect to the present experimental value. The lower compressibility of the octahedra is quantified with a splitting between octahedral and tetrahedral $B_{0}$ values of 63 $\mathrm{GPa}$. Note also that the average of the octahedral and tetrahedral $B_{0}$ values reproduces the value for the bulk. This result has been explained as a consequence of the low dependence of the parameter $u$ on pressure. ${ }^{23}$

One striking feature revealed from Figs. 2 and 3 is that the octahedral Si-N and N-N bond lengths are less compressible than the tetrahedral ones while for thermal expansion, the octahedral $\mathrm{Si}-\mathrm{N}$ and $\mathrm{N}-\mathrm{N}$ bond lengths are more expanding than the tetrahedral ones. The results indicate a different bond strength versus bond-length behavior for the octahedral and tetrahedral sites in the $c-\mathrm{Si}_{3} \mathrm{~N}_{4}$ phase. During compression, bond strength increases faster for the octahedral sites than the tetrahedral ones, with the result that the octahedral polyhedra are less compressible than the tetrahedral ones, as detected in Fig. 3. On the other hand, during thermal expansion the bond strength for the octahedral sites may increase more slowly than the tetrahedral ones. Consequently, the bond length for the octahedral site increases faster with temperature than the tetrahedral one, as observed experimentally in Fig. 2. The experimental results described here have already triggered further theoretical work on this matter.
*Corresponding author,: Department of Physics, Building 307, Technical University of Denmark, DK-2800 Lyngby, Denmark. FAX: +45 459323 99. Email address: jiang@fysik.dtu.dk

${ }^{1}$ A. Zerr et al., Nature (London) 400, 340 (1999).

${ }^{2}$ S. D. Mo et al., Phys. Rev. Lett. 83, 5046 (1999); W. Y. Ching et al., Phys. Rev. B 61, 8696 (2000).

${ }^{3}$ T. Sekine et al., Appl. Phys. Lett. 76, 3706 (2000).

${ }^{4}$ M. Schwarz et al., Adv. Mater. 12, 883 (2000).

${ }^{5}$ J. Z. Jiang et al., Europhys. Lett. 51, 62 (2000).

${ }^{6}$ C. M. Marian, M. Castreich, and J. D. Gale, Phys. Rev. B 62, 3117 (2000).

${ }^{7}$ H. He et al., Phys. Rev. B 62, 11412 (2000).

${ }^{8}$ E. Soignard et al., J. Phys.: Condens. Matter 13, 557 (2001).

${ }^{9}$ J. Z. Jiang et al., J. Phys.: Condens. Matter 13, L515 (2001).

${ }^{10}$ P. Mori-Sanchez et al., Europhys. Lett. 54, 760 (2001).

${ }^{11}$ T. Sekine et al., Appl. Phys. Lett. 78, 3050 (2001); I. Tanaka et al., ibid. 78, 2134 (2001).
${ }^{12}$ J. M. Leger et al., Nature (London) 383, 401 (1996).

${ }^{13}$ Y. Okada and Y. Tokumaru, J. Appl. Phys. 56, 314 (1984).

${ }^{14}$ H. K. Mao et al., J. Appl. Phys. 49, 3276 (1978).

${ }^{15}$ J. Z. Jiang et al., Phys. Rev. B 55, 14830 (1997).

${ }^{16}$ V. R. Saunders et al., CRYSTAL98 User's Manual (University of Torino, Torino, 1998).

${ }^{17}$ A. D. Becke, Phys. Rev. A 38, 3098 (1988); J. P. Perdew, in Electronic Structure of Solids, edited by P. Ziesche and H. Eschrig (Academic, Berlin, 1991).

${ }^{18}$ E. Francisco et al., J. Phys. Chem. A 102, 1595 (1998).

${ }^{19}$ I. C. Huseby, G. A. Slack, and R. H. Arendt, Bull. Am. Ceram. Soc. 60, 919 (1981).

${ }^{20}$ R. J. Bruls, H. T. Hintzen, G. de With, R. Metselaar, and J. C. van Miltenburg, J. Phys. Chem. Solids 62, 783 (2001).

${ }^{21}$ G. A. Slack and S. F. Bartram, J. Appl. Phys. 46, 89 (1975).

${ }^{22}$ F. Birch, J. Appl. Phys. 9, 279 (1938); Phys. Rev. 71, 809 (1947).

${ }^{23}$ J. M. Recio et al., Phys. Rev. B 63, 184101 (2001). 